\title{
BMJ Open Outcome measures for assessing the effectiveness of non-pharmacological interventions in frequent episodic or chronic migraine: a Delphi study
}

\author{
Kerstin Luedtke (D) , ${ }^{1,2}$ Annika Basener, ${ }^{2}$ Stephanie Bedei, ${ }^{2}$ Rene Castien, ${ }^{3}$ \\ Aleksander Chaibi (D) , ${ }^{4}$ Deborah Falla (iD , ${ }^{5}$ Cesar Fernández-de-las-Peñas, ${ }^{6}$ \\ Mirja Gustafsson, ${ }^{2}$ Toby Hall, ${ }^{7}$ Gwen Jull, ${ }^{8}$ Peter Kropp, ${ }^{9}$ Bjarne K Madsen, ${ }^{10}$ \\ Benjamin Schaefer, ${ }^{11}$ Elizabeth Seng, ${ }^{12}$ Claudia Steen, ${ }^{2}$ Peter Tuchin, ${ }^{13}$ \\ Harry von Piekartz, ${ }^{14}$ Bettina Wollesen ${ }^{15}$
}

To cite: Luedtke K, Basener A, Bedei S, et al. Outcome measures for assessing the effectiveness of non-pharmacological interventions in frequent episodic or chronic migraine: a Delphi study. BMJ Open 2020;10:e029855. doi:10.1136/ bmjopen-2019-029855

- Prepublication history for this paper is available online. To view these files, please visit the journal online (http://dx.doi. org/10.1136/bmjopen-2019029855).

Received 27 February 2019 Revised 16 December 2019 Accepted 17 December 2019

Check for updates

(C) Author(s) (or their employer(s)) 2020. Re-use permitted under CC BY-NC. No commercial re-use. See rights and permissions. Published by BMJ.

For numbered affiliations see end of article.

Correspondence to Professor Kerstin Luedtke; kerstin.luedtke@uni-luebeck.de

\section{ABSTRACT}

Objectives The aim of this Delphi survey was to establish an international consensus on the most useful outcome measures for research on the effectiveness of non-pharmacological interventions for migraine. This is important, since guidelines for pharmacological trials recommend measuring the frequency of headaches with $50 \%$ reduction considered a clinically meaningful effect. It is unclear whether the same recommendations apply to complementary (or adjunct) non-pharmacological approaches, whether the same cut-off levels need to be considered for effectiveness when used as an adjunct or stand-alone intervention, and what is meaningful to patients.

Setting University-initiated international survey. Participants The expert panel was chosen based on publications on non-pharmacological interventions in migraine populations and from personal contacts. 35 eligible researchers were contacted, 12 agreed to participate and 10 completed all 3 rounds of the survey. To further explore how migraine patients viewed potential outcome measures, four migraine patients were interviewed and presented with the same measurement tools as the researchers.

Procedures The initial Delphi round was based on a systematic search of the literature for outcome measures used in non-pharmacological interventions for headache. Suggested outcome measures were rated by each expert, blinded towards the other members of the panel, for its usefulness on a 5-point Likert scale ranging from definitely not useful to extremely useful. Results were combined using median values and IQRs. Tools rated overall as definitely or probably not useful were excluded from subsequent rounds. Experts further suggested additional outcome measures that were presented to the panel in subsequent rounds. Additionally, experts were asked to rank the most useful tools and provide information on feasible cut-off levels for effectiveness for the three highest ranked tools.

Results Results suggest the use of the Migraine Disability Assessment (MIDAS), Headache Impact Test (HIT-6) and headache frequency as primary outcome measures.

\section{Strengths and limitations of this study}

- This manuscript provides an international expert consensus on outcome measures for trials evaluating the effectiveness of a non-pharmacological intervention for the reduction of migraine symptoms.

- A Delphi survey with three rounds was conducted to reach a consensus.

- Additional patient experts views contributed to a broader understanding on useful outcome measures including aspects of quality of life and attackassociated fear.

- A limitation is that patients were not included in the Delphi process but interviewed on a separate occasion.

Patient experts suggested the inclusion of a measure of quality of life and evaluation of associated symptoms and fear of attacks.

Conclusions Recommendations are for the use of the MIDAS, the HIT- 6 and headache frequency, in combination with an outcome measure for quality of life. Associated symptoms and fear of attacks should also be considered as secondary outcomes, if relevant for the individual target population. The cut-off level for effectiveness should be lower for non-pharmacological interventions, especially when used as an adjunct to medication.

Trial registration number German Register of Clinical Trials (DRKS00011777)

\section{INTRODUCTION}

Migraine is a prevalent ${ }^{12}$ and disabling condition, ${ }^{3}$ with high socioeconomic costs mainly due to days off work. ${ }^{4-9}$ Migraine may become chronic when it occurs on $\geq 15$ days per month for at least 3 months with features of migraine in $\geq 8$ days. ${ }^{10}$

Guidelines for chronic and frequent episodic migraine recommend the use of nonpharmacological approaches as an adjunct 
or alternative to the first-line pharmacological management. ${ }^{11-16}$ Patients welcome this recommendation and usually report the use of complementary interventions to reduce the amount of acute pain medication. ${ }^{17}{ }^{18}$ Especially, those patients who do not tolerate acute and/or prophylactic medicine because of side effects, have contraindications due to co-morbidities or may wish to avoid medication for other reasons, seek non-pharmacological alternatives. ${ }^{1920}$ Recommended strategies include relaxation, cognitive-behavioural interventions and aerobic exercise; other interventions are mentioned but not recommended due to a lack of evidence for their effectiveness, ${ }^{11-16}$ primarily due to methodological shortcomings. ${ }^{2122}$

Additional research is urgently needed to identify whether these other non-pharmacological treatment strategies are effective to complement pharmacological managementas an adjunct or, in cases where patients do not tolerate acute and/or prophylactic medications because of side effects, have contraindications due to co-morbidities of other diseases or wish to avoid medication for other reasons, can manage their frequent episodic or chronic migraines prophylactically. However, before determining the effectiveness of either intervention, it is important to decide which outcome measures may be useful to indicate change following a non-pharmacological intervention in migraine patients. The International Headache Society (IHS) recommends the use of headache frequency as the primary outcome measure, usually assessed as headache days per month documented in a headache diary. ${ }^{23}$ However, this recommendation refers to studies investigating the effect of preventive medication. A guideline for behavioural trials confirms frequency as the primary outcome measure. ${ }^{24}$ No other clinical guidelines determining the main outcome for primary headache disorders exist for non-pharmacological trials. Additionally, no study has investigated whether the number of headache days is an improvement which is meaningful to patients. Therefore, it is unclear whether clinical trials investigating the effectiveness of treatments such as massage, passive mobilisation or manipulation, physical activity or any other non-pharmacological intervention as an adjunct or as a stand-alone intervention should also use headache frequency as a primary outcome measure, and at what cut-off level the intervention can be considered successful.

The cut-off level stated by the IHS and the guideline for behavioural treatment for the effectiveness of a treatment is a reduction of $\geq 50 \%$ of headache frequency. ${ }^{23} 24$ Both guidelines, however, acknowledge that these levels might be lowered for studies on chronic migraine populations or reported as 'somewhat improved' if a responder rate $>25 \%$ is reached. Non-pharmacological interventions have a low risk of adverse events (AEs) and are less expensive. Intuitively, these approaches should therefore not be measured on the same scale as preventive medication since medication has a high risk of AEs. To reach a $50 \%$ level of improvement is particularly unrealistic if non-pharmacological interventions are evaluated as an add-on to the pharmacological management, especially since the net effect would then need to reach $75 \%$.

The objective for this Delphi survey was to establish an international consensus on the most useful outcome measures for assessing the effectiveness of nonpharmacological interventions for frequent episodic or chronic migraine. A secondary aim of the Delphi study was to investigate whether the same level of improvement, that is, $\geq 50 \%$ in headache frequency, is required to conclude on its effectiveness as recommended for preventative migraine medication, when used as an adjunct or a stand-alone intervention.

\section{METHODS}

\section{Study design}

The methods for this Delphi survey were based on published guidelines ${ }^{25}$ as well as on previous research. ${ }^{26}$ The data collection was conducted between October 2016 and August 2017. Selection of experts was based on personal contacts and a systematic search for primary authors in peer-reviewed journals on non-pharmacological intervention studies in headache populations. It must be noted that there is no guideline to define who is an expert for a Delphi survey or how many experts are required. ${ }^{27}$ Participants remained anonymous during all rounds to allow the expression of their opinions without the influence of dominant characters. ${ }^{28}$ After the final round, all experts were invited to co-author the report and subsequently received a first draft for revision and a final draft for approval prior to submission. The survey procedures were predesigned and included the following steps:

I. The initial survey was guided by a systematic evaluation of the literature on non-pharmacological interventions for migraine. PubMed was searched for articles published prior to 01.04.2017 using the following search strategy:

((( (headache [Title/Abstract] OR migraine [Title/ Abstract])) AND ((aerobic training or sports or exercise or acupuncture or chiropractic spinal manipulative therapy or progressive muscle relaxation or behavioural migraine management or cognitive behavioural therapy or biofeedback or physical activity or transcutaneous electrical nerve stimulation)) AND adult Filters: Humans.

II. In the first Delphi round, experts were asked to rate the usefulness of the outcome measures identified in step 1 for the use in non-pharmacological trials for frequent episodic or chronic migraine, on a 5-point Likert scale (1='extremely useful', 2='useful', 3='do not know', $4=$ 'probably not useful', $5=$ ='definitely not useful'). Experts were further invited to provide and suggest additional outcome measurement tools that they also considered relevant. To allow for an informed decision on test properties and previous application in research, references were provided for each outcome measure. To promote a more reliable decision on outcome measures, experts were additionally asked to rank their three favourite tools 


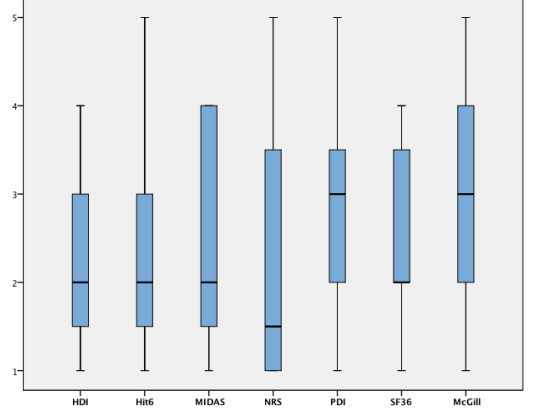

Figure 1 Results from the initial survey round. HDI, Henry Ford disability index; HIT-6, Headache impact test; McGill, McGill Pain Questionnaire; MIDAS, Migraine Disability Assessment Scale; NRS, Numerical Rating Scale; PDI, Pain Disability Index; SF-36, Short Form 36.

in a hierarchical order and to provide the cut-off levels for effectiveness which they perceived feasible for nonpharmacological interventions for frequent episodic or chronic migraine. The questionnaire used for the rating procedure was sent as a word document via email after it had been tested among working group members for comprehensibility. If individual ratings were missing or questionnaires were not returned, reminder emails were sent.

III. For the second round, group responses were analysed and fed back to the experts (via email) including the new tests suggested. These were again rated for their usefulness as in round one. To provide more information on the specific tools, experts were invited to comment on the individual tools.

IV. A third round was conducted in the same manner as the second round to include all new information that emerged from round two and to reach a final agreement.

V. Definition of consensus: no further rounds are conducted if no new outcome measures are suggested. Median values across experts were used to identify the most useful tools. Consensus on the relevance of an outcome measure was assumed if $75 \%$ of the participants rated the tool as 'useful' or 'extremely useful'. All outcome measures, rated as 'definitely not useful' or 'probably not useful' were excluded from subsequent Delphi rounds (based on the median value across experts). If multiple tools meet this definition of consensus, a hierarchical ranking was used to determine the tool considered most useful from the perspective of the experts in the panel.

\section{Data analysis}

All tools were analysed using the median and IQR across ratings and presented in box plots. Hierarchical ranking was analysed by allocating the highest-ranking tool 50 points, the second place 30 points and the third place 20 points. Sums across all ratings for each tool were calculated to identify the highest-ranking outcome measure. Comments on the outcome measures were summarised in a table with general quotes provided by the experts and for each tool.

\section{Patient and public involvement}

No patient involvement. Patient's views were expressed and integrated into the results as stated in the section on 'patients' views'.

\section{Patients' views}

Patients repeatedly stated that there was so much more to their suffering than the number of headache days in their diaries. Rather than including them in the Delphi process, patients were invited to take part as experts for their symptoms in this study by being interviewed. It was anticipated that patients' views were more multifaceted and diverse and that the ranking tasks requested during the Delphi rounds would do their opinions not sufficient justice. Therefore, in order to include the preferences of the target group, four women, known to the researchers from the university headache clinic, diagnosed with chronic migraine with $>10$ years history of migraine were recruited into the study. They were experienced in pharmacological and non-pharmacological trials and knowledgeable on a wide range of outcome measures throughout their experiences at a specialised university outpatient headache clinic. Patients were presented with the same outcome measures as the research experts and interviewed regarding their preference and opinion on the different tools. They were further asked whether they regarded $\mathrm{a} \geq 50 \%$ change in the number of headache days as an acceptable outcome level of improvement to justify a non-pharmacological treatment. Two patients were interviewed as a group to stimulate discussion and two were interviewed by telephone. Interviews were held at the outpatient headache clinic at the University Medical Center Hamburg-Eppendorf.

The interviews were recorded on a digital voice recorder. After the interviews, two researchers transcribed the interviews independently on personal computers to avoid potential risks of mishearing and misinterpretation. ${ }^{29}$ Transcripts were compared and discussed before they were coded and analysed.

A thematic analysis approach was used by categorising questions, themes and quotations. ${ }^{30}$ To focus on the research question, only those quotations were chosen in which the participants explained their views about the outcome measures.

\section{RESULTS}

\section{Sample characteristics}

A total of 35 international experts from seven countries were identified and invited via email to participate. The invitation included the researcher's details and meticulous information about the survey and the study design. Twelve experts agreed to participate and completed the first round, and 10 experts completed all three rounds of the survey.

\section{Delphi round 1}

The literature search identified seven different outcome measures used in studies evaluating the effectiveness of 
non-pharmacological interventions in migraine populations: Henry Ford-Hospital Headache Disability Inventory (HDI), Headache Impact Test (HIT-6), Migraine Disability Assessment (MIDAS), Numerical Rating Scale (NRS), Pain Disability Index (PDI), Short Form-36 (SF-36) and Short Form McGill Pain Questionnaire (SFMPQ). These instruments were evaluated by a panel of 12 experts (eight physiotherapists, two chiropractors, two psychologists). All experts had an academic degree equivalent to PhD except one expert with an MSc. From these seven initial tests, PDI and SF-MPQ showed a median value of 3 (rated by three and four experts, respectively, as 'do not know') while the remaining tests showed a median rating of 2 ('useful') (figure 1). No outcome measure was discharged after this initial round. The ranking task placed the MIDAS first, followed by the HIT- 6 and the NRS by the experts.

Ten additional outcome measures were suggested by the experts: Brief Pain Inventory, Craniofacial Pain and Disability Inventory (CF-PDI), Functional Disability Inventory (FDI), Fragebogen zu Kopfschmerzmanagement und Selbstwirksamkeit (FKMS), Headache Diary, Headache Frequency, Migraine Specific Quality of Life, Veterans RAND 12 Item Health Survey (VR-12), Rostocker Kopfschmerz-Fragenkomplex (RoKoKo) and DoloTest.

\section{Delphi round 2}

These outcome measures were rated by the experts participating in the second round $(n=10)$. Two ratings (one on the RoKoKo and one on the FKMS) were missing. From the 10 newly evaluated outcome measures, headache diary and headache frequency received median ratings of 'extremely useful', while CF-PDI and FDI were excluded as 'definitely not useful' and 'probably not useful', respectively (figure 2). There is no English version available for the RoKoKo and the FKMS, making the feasibility of this tool not useful for English-speaking researchers. Comments provided by experts were summarised in a table with numbers behind quotes indicating the number of experts who expressed this opinion (table 1).

The revised ranking based on outcome measures from rounds one and two indicated that the MIDAS was the most useful tool, followed by the HIT- 6 and the headache frequency. Headache diary, PDI and NPRS shared rank four. Suggested cut-off levels for each tool, indicating the acceptable effectiveness of a non-pharmacological intervention when used as an adjunct treatment to medication or as a stand-alone intervention, are listed in table 2.

\section{Results from the patient interviews}

All patients agreed that the SF-36 appeared to be the tool which best reflected their well-being. This was followed by the MIDAS, the HIT-6 and the HDI. The least useful tool from the patients' point of view were NRS and McGill.

Patients commented that some aspects of their migraine were missing in the measuring tools available. One patient stated that sometimes her aura was the dominant problem but that this was never mentioned as an option in any of the tools. Another patient suggested adding a measure for fear of the next migraine attack. The fear itself was sometimes more disabling than any other symptom for this patient.

When asked about the minimum relevant change levels acceptable, patients agreed that any improvement of any of their symptoms would justify seeking a nonpharmacological treatment. A 50\% reduction of headache days did not seem to be realistic for any patient for a non-pharmacological treatment. They explained how difficult it was to identify changes following a treatment because of the unpredictability of migraine. Quotations underlining the patients' points of view are presented in table 3 .

\section{DISCUSSION}

The present study reports on an international Delphi survey, aiming to reach consensus on the measurement tools to be used in non-pharmacological interventions for migraine. MIDAS, HIT- 6 and headache frequency reached the definition of consensus and were ranked as the most relevant tools by the Delphi participants; conversely, patients valued measures of quality of life higher and suggested to measure additional aspects such as fear of the next attack.

While the outcome measures that were suggested by experts in this study largely reflect those used in pharmacological trials, MIDAS and HIT-6 were prioritised over headache frequency, potentially indicating that aspects of suffering and disability were valued higher than the simple counting of headache days.

Expert opinions varied widely with most outcome measures receiving ratings ranging from 'extremely useful' to 'probably or definitely not useful', indicating that none of the suggested outcome measures was perceived as ideal. This is partially explained by comments from experts and two of the four patients stating that the MIDAS is often misunderstood and not answered correctly and should be simplified. Furthermore, recalling a 3-month period might introduce bias and reduce precision of the measurement. The general criticism about the HIT-6 was that it does not accommodate the complexity of migraine and its impact on individuals. To prevent researchers from using different tools in future research and thereby not allowing for the comparability of results, these limitations should be addressed by, for example, providing a version of the MIDAS only reflecting on the past 4 weeks rather than on the past 3 months.

The highest rated outcome measures also reflected those best evaluated in the literature. MIDAS has been validated and translated in many languages ${ }^{31-36}$ and has shown good psychometric properties. ${ }^{31-39}$ Similar research is available on HIT-6. ${ }^{34}{ }^{40-43}$ Some of the tools suggested were too specific for a particular pathology, such as the CF-PDI and FDI and are therefore only applicable in situations when painful temporomandibular dysfunctions play a dominant role. Others were too broad 
Table 1 Expert statements on outcome measures

\begin{tabular}{|c|c|c|}
\hline $\begin{array}{l}\text { Outcome } \\
\text { measure }\end{array}$ & Expert statement & $\begin{array}{l}\text { Ranking } \\
\text { after final } \\
\text { round }\end{array}$ \\
\hline MIDAS & $\begin{array}{l}\text { Useful tool for measuring disability (2) } \\
\text { Difficult to use it for non-pharmacological interventions (3) } \\
\text { Should be simplified (1) }\end{array}$ & 1 \\
\hline HIT-6 & $\begin{array}{l}\text { Short and simple to complete (1) } \\
\text { Disease-specific and includes functional and emotional disability (1) } \\
\text { Criticised for 'its ability to identify the complexity of impact with which headache has on individuals' (2) } \\
\text { In clinical practise this questionnaire is the most representative for change in headache frequency related to impact on } \\
\text { daily life (1) }\end{array}$ & 2 \\
\hline $\begin{array}{l}\text { Headache } \\
\text { frequency }\end{array}$ & $\begin{array}{l}\text { Difference to diaries? (1) } \\
\text { Primary efficacy outcome measurement in the first, second and third IHS clinical trial guideline, thus, it is highly relevant (1) }\end{array}$ & 3 \\
\hline NPRS & $\begin{array}{l}\text { Very important measurement (1) } \\
\text { Not useful (for headache) (3) } \\
\text { Unlikely to capture the overall impact of headache (1) } \\
\text { Depends on self-report (1) }\end{array}$ & 4 \\
\hline $\begin{array}{l}\text { Headache } \\
\text { diary }\end{array}$ & $\begin{array}{l}\text { Number } 1 \text { in research for chronic (migraine) headache (1) } \\
\text { Headache diaries are extremely effective in monitoring headache and migraine patients in terms of efficacy outcomes. (1) }\end{array}$ & 4 \\
\hline HDI & $\begin{array}{l}\text { Time consuming (2) } \\
\text { Good tool for measuring (perception) of disability (2) } \\
\text { Poorly validated (1) }\end{array}$ & 5 \\
\hline SF-36 & $\begin{array}{l}\text { Most useful tool for measuring general disability (4) } \\
\text { Not specific for headache/migraine (5) } \\
\text { Takes time to fill out (1) }\end{array}$ & 6 \\
\hline FKMS & $\begin{array}{l}\text { Unknown (2) } \\
\text { Probably not an outcome scale (1) }\end{array}$ & 7 \\
\hline CF-PDI & $\begin{array}{l}\text { Not familiar (1) } \\
\text { Specific for craniomandibular dysfunction not for headaches (2) }\end{array}$ & 7 \\
\hline VR 12 & Not a specific headache related questionnaire, but shows an insight in general health and well-being (3) & 8 \\
\hline SF-MPQ & $\begin{array}{l}\text { Not useful in headache/migraine (5) } \\
\text { Takes a lot of time and explanations (1) } \\
\text { Does not identify disability or the impact of headache on daily life (1) }\end{array}$ & 8 \\
\hline FDI & Not useful for chronic migraine, because it is focused on problems related to cranio-mandibular dysfunction (3) & 8 \\
\hline RoKoKo & Could not locate the English version (1) & 8 \\
\hline BPI & $\begin{array}{l}\text { Could be useful for patients with chronic migraine (1) } \\
\text { This questionnaire was developed for patients with cancer- the psychometric properties are not known for headache (1) } \\
\text { Not all questions are relevant to headache (1) } \\
\text { Not migraine-specific although it contains a few relevant questions (1) }\end{array}$ & 8 \\
\hline
\end{tabular}

Numbers behind statements indicate the number of experts expressing this opinion.

BPI, BriefPain Inventory; CF_PDI, Craniofacial Pain and Disability Inventory; FDI, Functional Disability Inventory; FKMS, Fragebogenzu Kopfschmerzmanagement und Selbstwirksamkeit; HDI, Henry Ford Disability Index; HIT-6, Headache Impact Test; IHS, International Headache Society; McGill, McGill Pain Questionnaire; MIDAS, Migraine Disability Assessment Scale; MSQ, Migraine Specific Quality of Life; NPRS, Numerical Pain Rating Scale; NRS, Numerical rating Scale; PDI, Pain Disability Index; RoKoKo, Rostocker Kopfschmerz-Fragenkomplex; SF-36, ShortForm 36; VAS, Visual Analog Scale; VR-12, Veterans RAND 12 Item Health Survey.

such as the SF-36 or VR-12 or PDI and therefore not considered as a specific outcome measure for studies on migraine. This might also be the reason, why no global rating tool, such as Patient Global Rating of Change was suggested or discussed by experts. Interestingly, patients viewed this topic differently by stating a clear preference for the SF-36. Patients also commented that the associated symptoms can be more disabling than the headache itself, such as the aura or fear of the next migraine attack. The migraine-specific quality of life questionnaire covers fear of the next attack and has been evaluated in various languages. ${ }^{44-50}$ It was initially unclear why the tool 


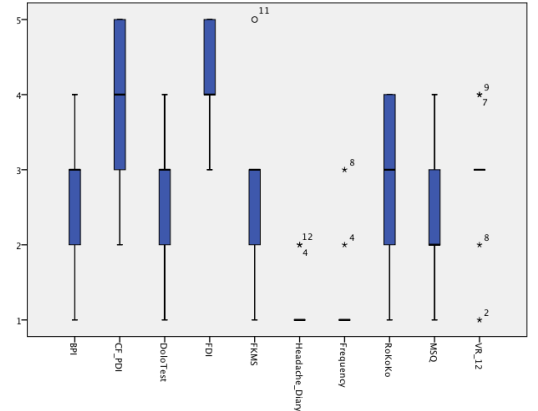

Figure 2 Results from the second survey round. BPI, Brief Pain Inventory; CF_PDI, Craniofacial Pain and Disability Inventory; FDI, Functional Disability Inventory; FKMS, Fragebogen zu Kopfschmerzmanagement und Selbstwirksamkeit; MSQ, Migraine Specific Quality of Life; RoKoKo, Rostocker Kopfschmerz-Fragenkomplex; VR-12, Veterans RAND 12 Item Health Survey.

was not popular with the experts in this study. Few had used it because although free for researchers, it is only available from the company GlaxoSmithKline and the included 25 items require more time than the MIDAS or the HIT-6. Fear of migraine can also be investigated by a 4-item tool which has recently been developed. ${ }^{51}$ This tool has not been used in previous published trials on non-pharmacological treatments and was not suggested by the Delphi panel. Associated symptoms have largely been ignored in research. Wang et al recently reported on the development of a tool to capture these symptoms, but psychometric properties and testing procedures are not yet available. ${ }^{52}$

The commonly agreed cut-off value for effectiveness in pharmacological trials is a $\geq 50 \%$ reduction in headache days $^{53}$ with an accepted reduction to a responder rate of $30 \%$ in chronic migraine populations. ${ }^{23}$ Previous research has identified the minimal clinically relevant change for HIT- 6 to be -2.5 to -6 points in migraine. ${ }^{42}$ No recommendation was identified for the MIDAS. A $\geq 50 \%$ reduction

Table 2 Suggested cut-off levels to indicate effectiveness

\begin{tabular}{ll}
\hline Outcome measure & $\begin{array}{l}\text { Suggested cut-off levels to } \\
\text { indicate effectiveness }\end{array}$ \\
\hline HIT-6 & $>25 \%(1)$ \\
Max. score 78 points & $>30 \%(1)$ \\
& $>50 \%(1)$ \\
& $>10$ points (1) \\
& $>6-8$ points (1) \\
MIDAS & $>10$ points (2) \\
Max. score 270 points & $>25 \%$ points (2) \\
& $>50 \%(2)$ \\
Headache frequency & $>25 \%(1)$ \\
Max. score 30/31 points &
\end{tabular}

The numbers behind the cut-off levels indicate the number of experts recommending this cut-off level.

Hit-6, Headache Impact Test; MIDAS, Migraine Disability

Assessment Scale. of headache frequency is a target that is difficult to reach with non-pharmacological interventions, especially when provided as an adjunct to preventive medication and especially in chronic migraine. Lowering the target should be considered, especially since AEs are few, mild and transient, ${ }^{54}$ and most of the interventions are low cost. However, based on the expert panel of this survey, there was no clear agreement on a specific cut-off level for any of the tools, but it seems that more realistic targets are needed to show the true effect of a non-pharmacological intervention. A limitation of the survey design was that cut-off levels for effectiveness were not distinguished for studies using non-pharmacological interventions as an adjunct treatment to, for example, prophylactic medication and studies using non-pharmacological interventions as a stand-alone treatment. However, in both situations a lower target should be used, since non-pharamcological interventions do not (or to a much lower extent) have to consider the trade-off between effect and side-effects. Patients confirmed that any small improvements of any of their symptoms would justify the time and money spent on the intervention.

For future research on non-pharmacological interventions for frequent episodic or chronic migraine, it is highly important to use the same primary and/or secondary outcome measure to be able to compare and combine results to reach a higher level of evidence that can subsequently be included in national and international guidelines. At this stage, there does not seem to be an ideal outcome measure. Neither does it seem to be clear which aspects of migraine (such as its intensity, its impact on a person's life, it's uncertainty...) are the most important aspects to be measured. Within these limitations and with the literature currently available, we promote the use of the MIDAS, the HIT- 6 and headache frequency, and an outcome measure for quality of life (eg, SF-36), which was preferred by patients and recently identified as a useful indicator for change,$^{55}$ in addition to the newest clinical guideline recommendations by the IHS ${ }^{53}$ when conducting future non-pharmacological randomised clinical trials in patients with frequent episodic or chronic migraine. Associated symptoms and fear of attacks should be considered as secondary outcomes.

We recognise some potential limitations of the current study. First, there was a limited number of experts available to complete all three rounds of the Delphi process. However, they represented different professional backgrounds and reflect the variability in non-pharmacological migraine-research. Only four patients were interviewed; these were chosen based on their longstanding migraine history and previous participation in research trials, thus, acquiring a high level of expertise on outcome measures in relation to their own suffering levels. Outcome measures were presented to experts in a non-randomised order. While this might influence responses, it also helped to keep experts oriented by using a standardised order of outcome measures and response options. 
Table 3 Patient perspective on suggested outcome measures

\begin{tabular}{|c|c|c|}
\hline Questions & Themes & Quotations \\
\hline \multirow[t]{5}{*}{$\begin{array}{l}\text { What is your first } \\
\text { impression of the } \\
\text { measuring tools? }\end{array}$} & MIDAS & $\begin{array}{l}\text { "...MIDAS is very common" } \\
\text { " } 3 \text { months is a difficult period of time to remember, symptoms can vary from month to } \\
\text { month" }\end{array}$ \\
\hline & HDI / HIT-6 & $\begin{array}{l}\text { "...I quite liked this one" } \\
\text { "...as well as the HIT-6" }\end{array}$ \\
\hline & NPRS & "some measures are just numbers, NRS does not measure anything, really" \\
\hline & $\begin{array}{l}\text { Headache } \\
\text { frequency / } \\
\text { diary }\end{array}$ & $\begin{array}{l}\text { "when a new study is published I always look at the reduction of days per month, so it } \\
\text { does seem important to count days" }\end{array}$ \\
\hline & SF36 & $\begin{array}{l}\text { "I liked the SF-36 best, because it includes quantity but also measures the burden of } \\
\text { migraine... and how I am" }\end{array}$ \\
\hline $\begin{array}{l}\text { What do you like / } \\
\text { dislike about these } \\
\text { tools? }\end{array}$ & Fear & $\begin{array}{l}\text { "I am always scared of the next attack - This fear is sometimes stronger than on } \\
\text { other days. I sometimes feel as if the fear is worse than the actual attack, because it } \\
\text { influences more or less every day of my life." }\end{array}$ \\
\hline $\begin{array}{l}\text { Is a } 50 \% \text { reduction } \\
\text { of headache days } \\
\text { realistic? }\end{array}$ & & $\begin{array}{l}\text { "(...) I currently have more frequent migraine attacks but the pain is not as intense as it } \\
\text { was. My aura, however, is more intense than ever, it sometimes occurs on } 15 \text { days in } \\
1 \text { month. I have also had months with only } 3 \text { days of aura and more headache. I find it } \\
\text { very difficult to estimate whether an intervention was effective because of this variability } \\
\text { in symptoms. The effect probably needs to be followed up over } 2 \text { years to identify } \\
\text { whether the reduction was one of the usual variations." } \\
\text { "If any medication would give me } 20 \% \text { reduction of symptoms I would be very very } \\
\text { happy! Any reduction is good!" }\end{array}$ \\
\hline
\end{tabular}

HDI, Henry Ford Disability Index; HIT-6, Headache Impact Test; MIDAS, Migraine Disability Assessment Scale; NRS, Numerical rating Scale.

\section{CONCLUSION}

There was some diversity between experts' and patients' opinions on the most important outcome measures for non-pharmacological trials. Recommendations are for the use of the MIDAS, the HIT-6 and headache frequency, in combination with an outcome measure for quality of life. Associated symptoms and fear of attacks should also be considered as secondary outcomes, if relevant for the individual target population. The cut-off level for effectiveness might be lower for non-pharmacological trials, especially when these are used as an adjunct to medication.

\section{Author affiliations}

${ }^{1}$ Pain and Exercise Research, Universitat zu Lubeck Sektion Medizin, Lubeck, Germany

${ }^{2}$ Department of Human Movement Science, University of Hamburg, Hamburg, Germany

${ }^{3}$ Amsterdam Public Health research institute, VU University Medical Center, Amsterdam, Netherlands
${ }^{4}$ Head and Neck Research Group, Research Centre Akershus University Hospital, Lørenskog, Oslo, Norway

${ }^{5}$ School of Sport, Exercise and Rehabilitation Sciences, University of Birmingham, Birmingham, UK

${ }^{6}$ Department of Physical Therapy, Occupational Therapy, Physical Medicine and Rehabilitation, Universidad Rey Juan Carlos, Alcorcón, Madrid, Spain

${ }^{7}$ School of Physiotherapy and Exercise Science, Curtin University, Perth, Western Australia, Australia

${ }^{8}$ Centre of Clinical Research Excellence in Spinal Pain, Injury and Health, The University of Queensland, Brisbane, Queensland, Australia

${ }^{9}$ Institut für Medizinische Psychologie und Medizinische Soziologie, University of Rostock, Rostock, Germany

${ }^{10}$ Danish Headache Center, Department of Neurology, University of Copenhagen, Kopenhagen, UK

${ }^{11}$ Migraine and Headache Clinic, Koenigstein/Taunus, Germany

${ }^{12}$ Albert Einstein College of Medicine, Montefiore Medical Center, Yeshiva University, New York, New York, USA

${ }^{13}$ Department of Chiropractic, Macquarie University, Sydney, New South Wales, Australia

${ }^{14}$ Hochschule Osnabruck, Osnabruck, Niedersachsen, Germany

${ }^{15}$ Department of Human Movement Science, University of Hamburg, Hamburg, Hamburg, Germany 
Twitter Deborah Falla @Deb_Falla

Acknowledgements We would particularly like to thank the four migraine patients who shared their expertise during the focus group meetings and the telephone interviews.

Contributors All authors contributed substantially to the acquisition, analysis and interpretation of data. All authors revised it critically for important intellectual content. All authors approved of the final version submitted. $\mathrm{KL}$ and BW had the research idea and supervised the master students $A B, S B, C S$ and MG who conducted the data acquisition. RC, AC, DF, CFdIP, TH, GJ, PK, BKM, BS, ES, PT and HvP were participants of the survey and after the data analysis invited to be coauthors of the paper to ensure that all statements were summarised correctly and to present the result as a recommendation supported by an international team of experts. As stated above, all authors substantially contributed to the manuscript by revising, writing and introducing ideas.

Funding The authors have not declared a specific grant for this research from any funding agency in the public, commercial or not-for-profit sectors.

Competing interests None declared.

Patient consent for publication Not required.

Ethics approval Ethical approval was granted by the local ethics authority (University of Hamburg, Germany, number 2017_89).

Provenance and peer review Not commissioned; externally peer reviewed.

Data availability statement All data relevant to the study are included in the article or uploaded as supplementary information.

Open access This is an open access article distributed in accordance with the Creative Commons Attribution Non Commercial (CC BY-NC 4.0) license, which permits others to distribute, remix, adapt, build upon this work non-commercially, and license their derivative works on different terms, provided the original work is properly cited, appropriate credit is given, any changes made indicated, and the use is non-commercial. See: http://creativecommons.org/licenses/by-nc/4.0/.

\section{ORCID iDs}

Kerstin Luedtke http://orcid.org/0000-0002-7308-5469

Aleksander Chaibi http://orcid.org/0000-0003-2566-5984

Deborah Falla http://orcid.org/0000-0003-1689-6190

\section{REFERENCES}

1 Smitherman TA, Burch R, Sheikh $\mathrm{H}$, et al. The prevalence, impact, and treatment of migraine and severe headaches in the United States: a review of statistics from national surveillance studies. Headache 2013;53:427-36.

2 Lyngberg AC, Rasmussen BK, Jørgensen T, et al. Has the prevalence of migraine and tension-type headache changed over a 12-year period? A Danish population survey. Eur J Epidemiol 2005;20:243-9.

3 Raggi A, Leonardi M, Bussone G, et al. A 3-month analysis of disability, quality of life, and disease course in patients with migraine. Headache 2013;53:297-309.

4 Berg J, Stovner LJ. Cost of migraine and other headaches in Europe. Eur J Neurol 2005;12 Suppl 1:59-62.

5 Bloudek LM, Stokes M, Buse DC, et al. Cost of healthcare for patients with migraine in five European countries: results from the International burden of migraine study (IBMS). J Headache Pain 2012;13:361-78.

6 Burton WN, Conti DJ, Chen C-Y, et al. The economic burden of lost productivity due to migraine headache: a specific worksite analysis. $J$ Occup Environ Med 2002;44:523-9.

7 Lanteri-Minet M. Economic burden and costs of chronic migraine. Curr Pain Headache Rep 2014;18:385.

8 Pradalier A, Auray J-P, El Hasnaoui A, et al. Economic impact of migraine and other episodic headaches in France: data from the GRIM2000 study. Pharmacoeconomics 2004;22:985-99.

9 Steiner TJ, Stovner LJ, Katsarava Z, et al. The impact of headache in Europe: principal results of the Eurolight project. $J$ Headache Pain 2014;15:31.

10 International Headache Society. Headache classification Committee of the International headache Society (IHS) the International classification of headache disorders, 3rd edition. Cephalalgia 2018;38:1-211.

11 Pryse-Phillips WE, Dodick DW, Edmeads JG, et al. Guidelines for the diagnosis and management of migraine in clinical practice. Canadian headache Society. CMAJ 1997;156:1273-87.
12 Pryse-Phillips WE, Dodick DW, Edmeads JG, et al. Guidelines for the nonpharmacologic management of migraine in clinical practice. Canadian headache Society. CMAJ 1998;159:47-54.

13 Pringsheim T, Davenport WJ, Mackie G, et al. Canadian headache Society guideline for migraine prophylaxis. Can J Neurol Sci J Can Sci Neurol 2012;39:S1-59.

14 AWMF, 2014. Available: http://www.awmf.org/leitlinien/aktuelleleitlinien/II-liste/deutsche-migraene-und-kopfschmerzgesellschaft. html

15 Mauskop A, Holland S, Silberstein SD. Evidence-Based guideline update: NSAIDs and other complementary treatments for episodic migraine prevention in adults: report of the Quality Standards Subcommittee of the American Academy of Neurology and the American headache Society. Neurology 2013;80:868-9.

16 Silberstein SD, Rosenberg J. Multispecialty consensus on diagnosis and treatment of headache. Neurology 2000;54:1553.

17 Gaul C, Eismann R, Schmidt T, et al. Use of complementary and alternative medicine in patients suffering from primary headache disorders. Cephalalgia 2009;29:1069-78.

18 Gaul C, Schmidt T, Czaja E, et al. Attitudes towards complementary and alternative medicine in chronic pain syndromes: a questionnairebased comparison between primary headache and low back pain. BMC Complement Altern Med 2011;11:89.

19 Diener H-C, Charles A, Goadsby PJ, et al. New therapeutic approaches for the prevention and treatment of migraine. Lancet Neurol 2015;14:1010-22.

20 Schulte LH, May A. Headache research in 2014: advancing migraine therapy. Lancet Neurol 2015;14:6-7.

21 Chaibi A, Russell MB. Manual therapies for primary chronic headaches: a systematic review of randomized controlled trials. $J$ Headache Pain 2014;15:67.

22 Luedtke K, Allers A, Schulte LH, et al. Efficacy of interventions used by physiotherapists for patients with headache and migrainesystematic review and meta-analysis. Cephalalgia 2016;36:474-92.

23 Silberstein S, Tfelt-Hansen P, Dodick DW, et al. Guidelines for controlled trials of prophylactic treatment of chronic migraine in adults. Cephalalgia 2008;28:484-95.

24 Penzien DB, Andrasik F, Freidenberg BM, et al. Guidelines for trials of behavioral treatments for recurrent headache, first edition: American headache Society behavioral clinical trials Workgroup. Headache 2005;45:S110-32.

25 Hasson F, Keeney S, McKenna H. Research guidelines for the Delphi survey technique. J Adv Nurs 2000;32:1008-15.

26 Luedtke K, Boissonnault W, Caspersen N, et al. International consensus on the most useful physical examination tests used by physiotherapists for patients with headache: a Delphi study. Man Ther 2016;23:17-24.

27 Hsu and Sandford. The Delphi technique: making sense of consensus. Pract Assess Res Eval 2007;12:1-8.

28 Askham J, Marteau T, et al. Consensus development methods, and their use in clinical Guideline development. Health Technol Assess 1998;2:1-88.

29 Gibbs GR, Data AQ, Publications S, 2008. Available: http://books. google.ca/books?id=EfAX3YYkrdcC

30 Braun V, Clarke V. Using thematic analysis in psychology. Qual Res Psychol 2006;3:77-101.

31 Zandifar A, Asgari F, Haghdoost F, et al. Reliability and validity of the migraine disability assessment scale among migraine and tension type headache in Iranian patients. Biomed Res Int 2014;2014:1-7.

32 Ertaș M, Siva A, Dalkara T, et al. Validity and reliability of the Turkish migraine disability assessment (MIDAS) questionnaire. Headache 2004;44:786-93.

33 ligaya M, Sakai F, Kolodner KB, et al. Reliability and validity of the Japanese migraine disability assessment (MIDAS) questionnaire. Headache 2003;43:343-52.

34 Magnoux E, Freeman MA, Zlotnik G. Midas and HIT-6 French translation: reliability and correlation between tests. Cephalalgia 2008;28:26-34.

35 Benz T, Lehmann S, Gantenbein AR, et al. Translation, cross-cultural adaptation and reliability of the German version of the migraine disability assessment (MIDAS) questionnaire. Health Qual Life Outcomes 2018;16:42.

36 Juyal R, Verma R, Garg RK, et al. Reliability and validity of Hindi translation of the migraine disability assessment and headache impact test- 6 questionnaires. Ann Indian Acad Neurol 2010;13:276-83.

37 Oikonomidi T, Vikelis M, Artemiadis A, et al. Reliability and validity of the Greek migraine disability assessment (MIDAS) questionnaire. Pharmacoecon Open 2018;2:77-85. 
38 Stewart WF, Lipton RB, Dowson AJ, et al. Development and testing of the migraine disability assessment (MIDAS) questionnaire to assess headache-related disability. Neurology 2001;56:S20-8.

39 Stewart WF, Lipton RB, Kolodner KB, et al. Validity of the migraine disability assessment (MIDAS) score in comparison to a diarybased measure in a population sample of migraine sufferers. Pain 2000;88:41-52.

40 Kawata AK, Coeytaux RR, DeVellis RF, et al. Psychometric properties of the HIT-6 among patients in a Headache-Specialty practice. Headache 2005;45:638-43.

41 Martin M, Blaisdell B, Kwong JW, et al. The short-form headache impact test (HIT-6) was psychometrically equivalent in nine languages. J Clin Epidemiol 2004;57:1271-8.

42 Smelt AFH, Assendelft WJJ, Terwee CB, et al. What is a clinically relevant change on the HIT-6 questionnaire? an estimation in a primary-care population of migraine patients. Cephalalgia 2014;34:29-36.

43 Zandifar A, Banihashemi M, Haghdoost F, et al. Reliability and validity of the Persian HIT-6 questionnaire in migraine and tension-type headache. Pain Practice 2014;14:625-31.

44 Raggi A, Giovannetti AM, Schiavolin S, et al. Validating the migrainespecific quality of life questionnaire v2.1 (MSQ) in Italian inpatients with chronic migraine with a history of medication overuse. Qual Life Res 2014;23:1273-7.

45 Jhingran P, Davis SM, LaVange LM, et al. MSQ: migraine-specific quality-of-life questionnaire. Further investigation of the factor structure. Pharmacoeconomics 1998;13:707-17.

46 Jhingran P, Osterhaus JT, Miller DW, et al. Development and validation of the migraine-specific quality of life questionnaire. Headache 1998;38:295-302.
47 Cole JC, Lin P, Rupnow MFT. Minimal important differences in the migraine-specific quality of life questionnaire (MSQ) version 2.1. Cephalalgia 2009;29:1180-7.

48 Bagley CL, Rendas-Baum R, Maglinte GA, et al. Validating migrainespecific quality of life questionnaire v2.1 in episodic and chronic migraine. Headache 2012;52:409-21.

49 Rendas-Baum R, Bloudek LM, Maglinte GA, et al. The psychometric properties of the migraine-specific quality of life questionnaire version 2.1 (MSQ) in chronic migraine patients. Quality of Life Research 2013;22:1123-33.

50 Seo J-G, Park S-P. Validation of the Korean migraine-specific quality of life questionnaire version 2.1 in episodic and chronic migraine. $J$ Oral Facial Pain Headache 2017;31:251-6.

51 Giannini G, Zanigni S, Grimaldi D, et al. Cephalalgiaphobia as a feature of high-frequency migraine: a pilot study. J Headache Pain 2013;14:49.

52 Wang J, Zhang B, Shen C, et al. Headache symptoms from migraine patients with and without aura through structure-validated selfreports. BMC Neurol 2017;17:193.

53 Tfelt-Hansen P, Pascual J, Ramadan N, et al. Guidelines for controlled trials of drugs in migraine: third edition. A guide for Investigators. Cephalalgia Int J Headache 2012;32:6-38.

54 Chaibi A, Benth Jūratė Šaltytè, Tuchin PJ, et al. Adverse events in a chiropractic spinal manipulative therapy single-blinded, placebo, randomized controlled trial for migraineurs. Musculoskeletal Science and Practice 2017;29:66-71.

55 Probyn K, Bowers H, Mistry D, et al. Non-Pharmacological selfmanagement for people living with migraine or tension-type headache: a systematic review including analysis of intervention components. BMJ Open 2017;7:e016670. 